\title{
Economic burden of resected squamous cell carcinoma of the head and neck in an incident cohort of patients in the UK
}

\author{
Kun Kim", Mayur M Amonkar², Daniel Högberg ${ }^{1}$ and Frida Kasteng ${ }^{3}$
}

\begin{abstract}
Background: SCCHN is the sixth most common cancer worldwide. Locally advanced SCCHN continues to be a therapeutic challenge with high rates of morbidity and mortality and a low cure rate. Despite the apparent impact of SCCHN on patients and presumably society, the economic burden of the treatment of resected SCCHN patients in the UK has not been investigated.
\end{abstract}

Methods: This retrospective data analysis was based on in- and outpatient care records extracted from Hospital Episode Statistic database and linked to mortality data in the UK. SCCHN patients with resection of lip, tongue, oral cavity, pharynx or larynx were followed for at least one year (max. of 5 years) from the date of first resection.

Results: A total of 11,403 patients (mean age 63.2 years, $69.8 \%$ males) who met study criteria were followed for an average of 31 months. $32.3 \%$ of patients died in the follow-up period and the mean time to death was 16.9 months. In the first year, mean number of days of hospitalization and number of outpatient visits was 21.6 and 4.2, respectively; mean number of reconstructive and secondary surgeries was 0.32 and 0.14 per patient, respectively; $4.7 \%$ of the patients received radiotherapy and $12.2 \%$ received chemotherapy. From the second to fifth year healthcare utilizations rates were lower. Mean cost of post-operative healthcare utilization was $£ 23,212$ over 5 years ( $£ 19,778$ for the first year and $£ 1477, £ 847, £ 653$ and $£ 455$ for years $2-5$ ). Total cost of post-operative healthcare utilisation was estimated to be $£ 255.5$ million over the 5 -year follow-up.

Conclusions: In the UK, SCCHN patients after surgical resection needed considerable healthcare resources and incurred substantial costs. Study findings might provide a useful source for clinicians and decision makers in understanding the economic burden of managing SCCHN in the UK and also suggests a need for new therapies that could improve outcomes and reduce the disease burden.

Keywords: Squamous cell carcinoma of head and neck, Head and neck cancer, Oral cancer, Resection, Surgery, Cost of illness, Burden of illness

\section{Background}

Head and neck cancer (HNC) is a group of biologically similar cancers originating from the upper aerodigestive tract at various sites including the lips, oral cavity, nasal cavity, salivary glands, paranasal sinuses, thyroid, pharynx, and larynx. In the last 10 years, HNC has been one of the 10 most frequently diagnosed malignancies worldwide, with more than 640,000 people diagnosed and causing 7,500 deaths yearly [1]. In the UK, 7,538 people were

\footnotetext{
* Correspondence: kun.kim@i3innovus.com

'Optumlnsight, Stockholm, Sweden

Full list of author information is available at the end of the article
}

newly diagnosed with HNC in 2006 and 2,594 people died from the disease in 2007 [2]. Recent trend studies reported that the incidence of HNC has risen over the last 20 years in the UK [3-7]. One of the findings showed that the incidence rate of oral and oropharyngeal cancer rose from 6.5 to 8.3 per 100,000 men and from 2.6 to 3.6 per 100,000 women between 1990-1999 [3]. According to a study of mortality in oral cancer in Europe, the age adjusted mortality rate in England and Wales was 2.7 and 1.05 per 100,000 inhabitants in men and women respectively and in Scotland the age adjusted mortality rate was 4.6 and 1.6 per 100,000 inhabitants in men and women,

\section{Biomed Central}

(c) 2011 Kim et al; licensee BioMed Central Ltd. This is an Open Access article distributed under the terms of the Creative Commons Attribution License (http://creativecommons.org/licenses/by/2.0), which permits unrestricted use, distribution, and reproduction in any medium, provided the original work is properly cited. 
respectively between 1995-1999 [8]. In a projection of major cancers in the UK during 2006-2025, the mortality rate for oral cancer was estimated to still be growing in men and to be nearly constant in women [9].

The treatment of squamous cell carcinoma of the head and neck (SCCHN) is complex, partly because of the variety of tumor subsites and also because of the anatomic constraints of the head and neck region, together with the importance of maintaining organ function. Approximately $30-40 \%$ of patients with SCCHN present an early stage disease which is commonly managed by surgery (referred to as resection) or adjuvant radiotherapy with curative intent. For patients with advanced locoregionally disease without distant metastases, combinations of surgery, radiotherapy, and chemotherapy are used with the objective to maximize cure and maintain functional status through organ preservation. For patients with unresectable SCCHN, concurrent chemoradiotherapy is often chosen as a palliative treatment and may result in improved survival.

Although therapeutic advances have expanded treatment options, surgical resection is still considered an important treatment modality for SCCHN. The traditional treatment modality with surgical resection has a poor prognosis, $10-15 \%$ risk for local disease recurrence and $20-30 \%$ risk for disease progression within one year of treatment. According to a population-based study in Denmark, 1-year relative survival of patients with oral and pharynx cancer was $70 \%$ and $73 \%$ and the 5 -year relative survival was $33 \%$ and $42 \%$ in men and women respectively [10]. Besides, surgery for oral cavity and oropharynx cancer was found to immediately cause impairment in physical, emotional and social functions and severely compromise the patient's quality of life (QoL) [11]. Overall QoL scores of patients with SCCHN were significantly worse at 3 and 6 months and returned to around preoperative scores at 12 months after treatment $[12,13]$. However, the patients with oral cancer, who were treated with surgery, did not restore preoperational level of function in appearance, swallowing, recreation, and chewing [14-16] and no significant overall improvement was found at 12 months among patients who underwent free-flap surgery or total laryngectomy [17-22]. Finally, the treatment is burdensome on those who survive. According to findings from registry data among SCCHN patients after treatment, $55 \%$ patients had a feeding tube placed, $13 \%$ needed a tracheotomy, $79 \%$ required opioid analgesics, and $78 \%$ had anti-emetics prescribed, and $34 \%$ reported grade 3-4 mucositis/stomatitis [23].

Despite the apparent impact of the disease on patients and presumably on society and health care, the economic burden of the treatment of resected SCCHN patients in the UK has not been investigated. Therefore, this study aimed at identifying the post-operative healthcare utilisation and its associated cost for an incident cohort of patients with SCCHN in the UK who underwent surgical resection.

\section{Methods}

A retrospective analysis was performed by using Hospital Episode Statistic (HES) data, which covers all National Health Service (NHS) trusts and independent sectors in the UK. The scope of the data included secondary care facilities such as care trusts, mental health trust, NHS trust, ambulance trusts and emergency and urgent care but it did not include primary care facilities such as NHS direct/clinic centers, GP practices, dentists, opticians and pharmacists and also did not include accident and emergency care. The NHS data quality report concluded that HES data was a reliable source for activity-based analyses at national level in a provider's perspective based on high levels of completeness and validity for most fields related to patient identification in both inpatient and outpatient care [24]. However, the HES accident and emergency data still needs to be attested with reliability of the data [25] so it was not used in this analysis. The healthcare utilisation for patients in the HES data was identified with OPCS-4.5 codes which stores up individual procedures and interventions provided from inpatient and outpatient care. Mortality data between 2003 and 2009, provided by the Office for National Statistics (ONS), was used to identify deceased patients in the HES data. The requested data from HES and ONS were anonymized records, thus no patient's identity were disclosed for the purposes of this analysis.

The HES data was extracted from April 1, 2003 to March 31, 2009 and the data included patients who met the following inclusion criteria; evidence of cancer as primary diagnosis in lip, tongue, oral cavity, pharynx or larynx (ICD-10: C00-6, C09-10, C12-4, C32) and evidence of surgical resection from July 1, 2003 to March 31, 2008. The surgical resection was defined as including incision, excision, removal of foreign body, extirpation or -ectomy in respiratory tract, mouth, skin, soft tissue or bones and joints of skull of the patients. The selected patients were followed from the earliest date (index date) with the procedure code for primary surgical resection for at least 12 months or to the date of death or at the latest March 31, 2009. Patients who underwent resection between April 1, 2003 and June 30, 2003 were excluded to ensure that the patient would not be followed from a secondary resection. Patients under the age of 18 years were excluded. Figure 1 depicts the study observation period.

Post-operative healthcare utilization included the number of days of hospitalisation, the number of visits in outpatient care and treatments for chemotherapy-related adverse events. The chemotherapy-related treatments were identified by an episode of disease including anemia, neutropenia, thrombocytopenia, nausea, mucositis and 


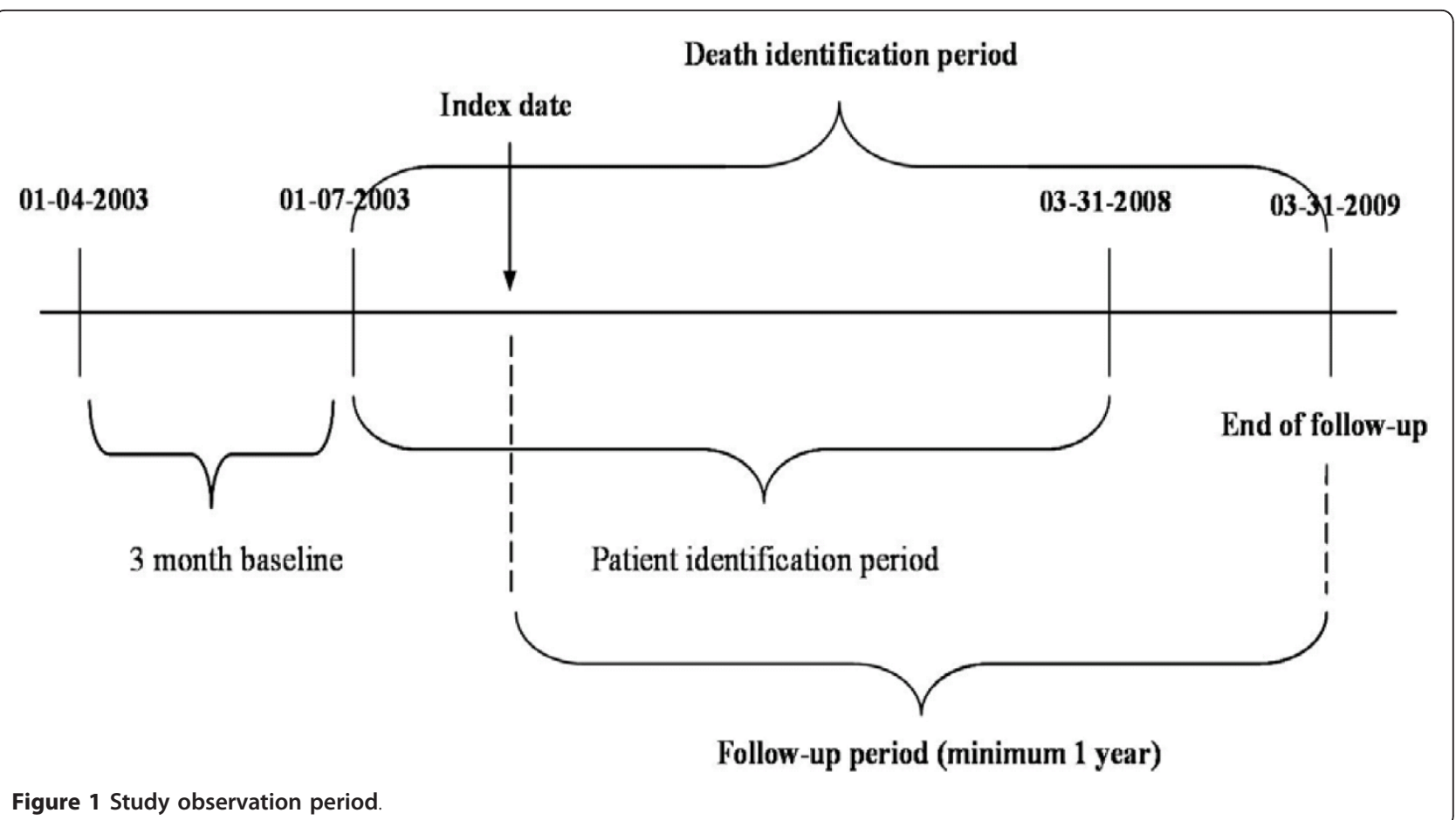

pain rather than a specific treatment. The post-operative healthcare utilization also included the number of radiotherapy and chemotherapy sessions and secondary or reconstructive surgeries after resection. The secondary surgery was defined as resection following a primary resection. The reconstructive resection was defined as including plasty, plastic repair, reconstruction, and flap in respiratory tract, mouth, skin, soft tissue or bones and joints of skull of the patients.

The post-operative healthcare cost was measured by mapping the healthcare utilization to "the national schedule of reference costs 2008-09 for NHS Trusts" and "Unit costs of health \& social care 2009" published by the Personal Social Services Research Unit (PSSRU). The unit costs for each procedure from inpatient and outpatient care are described in Additional file 1.

To account for the censored patients due to different lengths of follow-up in the data, the Kaplan-Meier sample-average (KMSA) method was employed. The KMSA is a technique to provide a consistent estimator of costs in the presence of censoring in the sample population [26]. The follow-up period was divided into each year and the mean cost of all uncensored patients during the each year was multiplied by the Kaplan-Meier estimate of the proportion alive at the beginning of the each year. Summing across these weighted costs for each interval resulted in the adjusted costs for censoring. The healthcare utilization and its costs were calculated in the first, second, third, fourth and fifth year from resection. The utilization and costs were to be interpreted as per year in the follow-up period for a group of the patients (incident cases) who were followed more than 1 year and less than 5 years.

\section{Results}

A total of 38,460 patients who were diagnosed with SCCHN from April 1, 2003 to March 31, 2009 were extracted from the HES data. 14,764 patients (38.4\%) underwent a surgical resection. Among the resected patients, we excluded 739 patients who underwent resection between April 1 and June 30, 2003. 2,599 patients who underwent resection after March 31, 2008 were also excluded as they had less than 12 months follow-up from the first resection. After excluding a further 23 patients, who were under the age of 18 years, 11,403 patients were finally included in the sample population. Figure 2 presents the flow chart for selection of the incident cohort of patients included in this study.

\section{Patient Cohort Characteristics}

The mean age of the patient cohort for this study was 63.2 years (SD 12.6) and $69.8 \%$ of patients were men. The mean age, the ratio of men to women and the proportion of age groups in the population corresponded to UK incidence statistics for HNC reported by Cancer Research UK $[27,28]$. Lip cancer patients were the oldest (mean 69.6 years) compared to the other four cancer sites while the larynx cancer subgroup had the largest percentage of males (85\%). The mean length of follow-up was 31.0 months (SD 18.4). The HES data were extracted mainly 


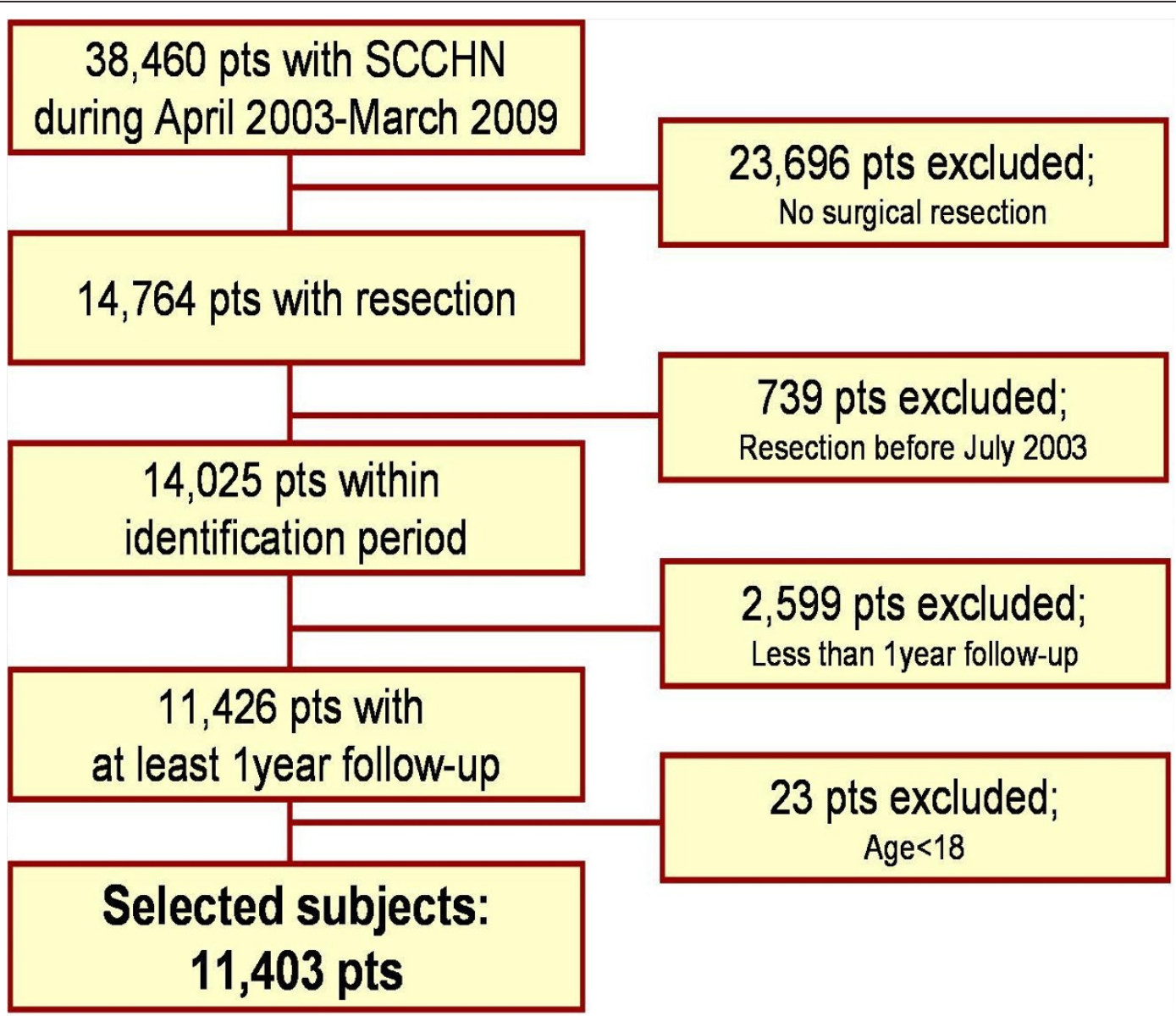

Figure 2 Sample selection and attrition flow chart.

from healthcare facilities in England. A majority of the patients in the population came from England and there were a minority from Scotland, Wales and Northern Ireland. Larynx cancer patients accounted for $29 \%$ and pharynx cancer patients for $20 \%$ of the cohort. Oral cavity, tongue and lip cancers patients accounted for $21 \%$, $19 \%$ and $11 \%$, respectively (Table 1 ). A total of 3,686 deaths were identified during follow-up and the mean length from first resection to death was 16.9 months. $46.3 \%$ of the deaths occurred within the first year of follow up with the highest and lowest percentage of deaths occurring with the pharyngeal (47.9\%) and lip cancer (31.5\%) cohorts, respectively. The highest percentage of deaths occurred among larynx cancer patients (37.3\%), followed by pharynx (35.4\%), oral cavity (32.7\%), tongue (30.3\%) and lip cancer patients (16.2\%) (Table 2).

\section{Estimation of survival over 5-year follow-up}

To calculate the total cost of the post-operative healthcare utilisation over the 5-year follow-up, the number of surviving patients during the 5-year follow-up was estimated, based on the number of followed patients and the number of deaths in the population. The number of surviving patients was assumed to be equal to the number of patients surviving the previous year deducted by the number of deaths among both the followed patients and the censored patients at the previous year. The number of deaths among the censored patients was estimated by the proportion of deaths in the followed patients multiplied with the number of the censored patients. At the beginning of the follow-up, there were 11,403 patients in the cohort. Since all subjects were followed at least 1 year, there was no censored patient and there were 9,697 surviving patients at the beginning of the second year in the cohort. The number of surviving patient per the rest of year was estimated as described (Table 3). The total cost of the post-operative healthcare utilisation was calculated by multiplying the mean costs in each year with the number of surviving patients in each year.

Post-operative healthcare utilisation

In the first year, the mean number of days of hospitalisation was 21.6 and the mean number of outpatient visits 
Table 1 Patient cohort characteristics

\begin{tabular}{|c|c|c|c|c|c|c|c|c|c|c|c|c|}
\hline \multirow[t]{3}{*}{ Cancer site } & \multicolumn{2}{|c|}{ Lip } & \multicolumn{2}{|c|}{ Tongue } & \multicolumn{2}{|c|}{ Oral cavity } & \multicolumn{2}{|c|}{ Pharynx } & \multicolumn{2}{|c|}{ Larynx } & \multicolumn{2}{|c|}{ SCCHN } \\
\hline & $\mathrm{N}$ & $\%$ & $\mathbf{N}$ & $\%$ & $\mathrm{~N}$ & $\%$ & $\mathrm{~N}$ & $\%$ & $\mathrm{~N}$ & $\%$ & $\mathrm{~N}$ & $\%$ \\
\hline & 1,250 & 11.0 & 2,167 & 19.0 & 2,372 & 20.8 & 2,304 & 20.2 & 3,310 & 29.0 & 11,403 & 100.0 \\
\hline Gender (Male) & 726 & 58.1 & 1,267 & 58.5 & 1,436 & 60.5 & 1,717 & 74.5 & 2,813 & 85.0 & 7,959 & 69.8 \\
\hline \multicolumn{13}{|l|}{ Age group } \\
\hline $18-44$ & 72 & 5.8 & 213 & 9.8 & 159 & 6.7 & 230 & 10.0 & 86 & 2.6 & 760 & 6.7 \\
\hline $45-64$ & 328 & 26.2 & 1,062 & 49.0 & 1,221 & 51.5 & 1,459 & 63.3 & 1,499 & 45.3 & 5,569 & 48.8 \\
\hline $65+$ & 849 & 67.9 & 892 & 41.2 & 991 & 41.8 & 615 & 26.7 & 1,725 & 52.1 & 5,072 & 44.5 \\
\hline \multicolumn{13}{|l|}{ Geographic location } \\
\hline North East & 96 & 7.7 & 109 & 5.0 & 167 & 7.0 & 160 & 6.9 & 280 & 8.5 & 812 & 7.1 \\
\hline North West & 214 & 17.1 & 332 & 15.3 & 447 & 18.8 & 399 & 17.3 & 548 & 16.6 & 1,940 & 17.0 \\
\hline Merseyside & 0 & 0.0 & 0 & 0.0 & 0 & 0.0 & 0 & 0.0 & 0 & 0.0 & 0 & 0.0 \\
\hline $\begin{array}{l}\text { Yorkshire and } \\
\text { Humber }\end{array}$ & 121 & 9.7 & 225 & 10.4 & 276 & 11.6 & 256 & 11.1 & 375 & 11.3 & 1,253 & 11.0 \\
\hline East Midlands & 112 & 9.0 & 212 & 9.8 & 245 & 10.3 & 244 & 10.6 & 269 & 8.1 & 1,082 & 9.5 \\
\hline West Midlands & 92 & 7.4 & 206 & 9.5 & 228 & 9.6 & 170 & 7.4 & 300 & 9.1 & 996 & 8.7 \\
\hline East of England & 147 & 11.8 & 204 & 9.4 & 185 & 7.8 & 207 & 9.0 & 304 & 9.2 & 1,047 & 9.2 \\
\hline London & 134 & 10.7 & 280 & 8.3 & 291 & 12.3 & 269 & 11.7 & 431 & 13.0 & 1,305 & 11.4 \\
\hline South East & 169 & 13.5 & 338 & 15.6 & 279 & 11.8 & 289 & 12.5 & 437 & 13.2 & 1,512 & 13.3 \\
\hline South West & 156 & 12.5 & 225 & 10.4 & 209 & 8.8 & 272 & 11.8 & 302 & 9.1 & 1,164 & 10.2 \\
\hline Scotland & 1 & 0.1 & 4 & 0.2 & 4 & 0.2 & 2 & 0.1 & 0 & 0.0 & 11 & 0.1 \\
\hline No fixed above & 0 & 0.0 & 2 & 0.1 & 0 & 0.0 & 3 & 0.1 & 2 & 0.1 & 7 & 0.1 \\
\hline Wales & 6 & 0.5 & 9 & 0.4 & 12 & 0.5 & 16 & 0.7 & 13 & 0.4 & 56 & 0.5 \\
\hline $\begin{array}{l}\text { Foreign (including } \\
\text { Isle of Man and } \\
\text { Channel Islands) }\end{array}$ & 1 & 0.0 & 18 & 0.8 & 21 & 0.9 & 14 & 0.6 & 40 & 1.2 & 93 & 0.8 \\
\hline Unknown & 1 & 0.0 & 3 & 0.1 & 8 & 0.3 & 3 & 0.1 & 8 & 0.2 & 22 & 0.2 \\
\hline \multirow[t]{2}{*}{ Northern Ireland } & 0 & 0.0 & 0 & 0.0 & 0 & 0.0 & 0 & 0.0 & 1 & 0.0 & 1 & 0.0 \\
\hline & Mean & SD & Mean & SD & Mean & SD & Mean & SD & Mean & SD & Mean & SD \\
\hline Age & 69.6 & 13.9 & 61.8 & 13.7 & 62.8 & 12.5 & 58.3 & 11.1 & 65.4 & 10.7 & 63.2 & 12.6 \\
\hline Length of follow-up (months) & 34.9 & 16.9 & 31.4 & 18.3 & 30.8 & 18.5 & 30.1 & 18.3 & 30 & 18.7 & 31 & 18.4 \\
\hline
\end{tabular}

was 4.2 in the population. The number of reconstructive surgeries was 0.32 per patient and the number of secondary surgeries was 0.14 per patient. $4.7 \%$ of the patients received radiotherapy and $12.2 \%$ of the patients received chemotherapy in either an inpatient or outpatient setting.
There were a total of 5,152 radiotherapy sessions and 5,153 chemotherapy sessions in inpatient and outpatient care. Half of the patients treated with chemotherapy were admitted due to chemotherapy-related conditions (Figure 3, 4).

Table 2 Number of deaths identified by year and cancer type

\begin{tabular}{|c|c|c|c|c|c|c|c|c|c|c|c|c|}
\hline Cancer site & \multicolumn{2}{|c|}{$\begin{array}{c}\text { Lip } \\
(\mathrm{N}=1,250)\end{array}$} & \multicolumn{2}{|c|}{$\begin{array}{c}\text { Tongue } \\
(\mathrm{N}=2,167)\end{array}$} & \multicolumn{2}{|c|}{$\begin{array}{l}\text { Oral cavity } \\
(\mathrm{N}=2,372)\end{array}$} & \multicolumn{2}{|c|}{$\begin{array}{c}\text { Pharynx } \\
(\mathrm{N}=2,304)\end{array}$} & \multicolumn{2}{|c|}{$\begin{array}{c}\text { Larynx } \\
(\mathrm{N}=3,310)\end{array}$} & \multicolumn{2}{|c|}{$\begin{array}{c}\text { SCCHN } \\
(\mathrm{N}=11,403)\end{array}$} \\
\hline Length of time to death ${ }^{1,2}$ & Mean & SD & Mean & SD & Mean & SD & Mean & SD & Mean & SD & Mean & SD \\
\hline & 22.4 & 15.3 & 16.4 & 13.3 & 17.4 & 14.1 & 16.4 & 13.4 & 16.4 & 13.6 & 16.9 & 13.8 \\
\hline \multirow[t]{2}{*}{ Number of deaths ${ }^{3}$} & $\mathrm{~N}$ & $\%$ & $\mathrm{~N}$ & $\%$ & $\mathrm{~N}$ & $\%$ & $\mathrm{~N}$ & $\%$ & $\mathrm{~N}$ & $\%$ & $\mathrm{~N}$ & $\%$ \\
\hline & 203 & 16.2 & 656 & 30.3 & 776 & 32.7 & 815 & 35.4 & 1,236 & 37.3 & 3,686 & 32.3 \\
\hline 1 year & 64 & 31.5 & 310 & 47.3 & 360 & 46.4 & 390 & 47.9 & 582 & 47.1 & 1,706 & 46.3 \\
\hline 2 year & 60 & 29.6 & 197 & 30.0 & 213 & 27.4 & 230 & 28.2 & 344 & 27.8 & 1,044 & 28.3 \\
\hline 3 year & 36 & 17.7 & 82 & 12.5 & 105 & 13.5 & 117 & 14.4 & 180 & 14.6 & 520 & 14.1 \\
\hline 4 year & 27 & 13.3 & 47 & 7.2 & 65 & 8.4 & 51 & 6.3 & 84 & 6.8 & 274 & 7.4 \\
\hline 5 year & 16 & 7.9 & 20 & 3.0 & 33 & 4.3 & 27 & 3.3 & 46 & 3.7 & 142 & 3.9 \\
\hline
\end{tabular}

${ }^{1}$ months; ${ }^{2}$ among the deceased patients; ${ }^{3}$ for year wise-breakdown \%s are based on number of deaths within a category 
Table 3 Total number of deaths and the estimation of survived patients by year

\begin{tabular}{|c|c|c|c|c|c|c|c|}
\hline Year & $\begin{array}{l}\text { No. of } \\
\text { patient } \\
\text { followed }\end{array}$ & $\begin{array}{l}\text { No. of } \\
\text { deaths } \\
\text { identified }\end{array}$ & $\begin{array}{l}\text { No. of patient } \\
\text { censored per } \\
\text { year }^{1}\end{array}$ & $\begin{array}{l}\text { Mortality } \\
\text { rate per } \\
\text { year }^{2}\end{array}$ & $\begin{array}{l}\text { No. of death among } \\
\text { censored patients }\end{array}$ & $\begin{array}{l}\text { No. of survived patient } \\
\text { estimated by KMSA }{ }^{4}\end{array}$ & $\begin{array}{l}\text { Cumulative } \\
\text { survival, all-causes } \\
\text { (\%) }\end{array}$ \\
\hline $\begin{array}{c}1 \\
\text { year }\end{array}$ & 11,403 & 1,706 & 0 & $15.0 \%$ & 0 & 11,403 & - \\
\hline $\begin{array}{c}2 \\
\text { year }\end{array}$ & 9,697 & 1,044 & 2,046 & $10.8 \%$ & 220 & 9,697 & $85.0 \%$ \\
\hline $\begin{array}{c}3 \\
\text { year }\end{array}$ & 6,607 & 520 & 1,767 & $7.9 \%$ & 139 & 8,433 & $74.0 \%$ \\
\hline $\begin{array}{c}4 \\
\text { year }\end{array}$ & 4,320 & 274 & 1,592 & $6.3 \%$ & 101 & 7,774 & $68.2 \%$ \\
\hline $\begin{array}{c}5 \\
\text { year }\end{array}$ & 2,454 & - & - & - & - & 7,399 & $64.9 \%$ \\
\hline
\end{tabular}

${ }^{1}=$ No. of followed patient - No. of followed patient at next year - No. of death

$2^{2}=$ No. of death/No. of followed patient

${ }^{3}=$ No. of censored patient ${ }^{*}$ mortality rate per year

${ }^{4}=$ No. of patient at previous year - No. of death at previous year - No. of death among censored patient at previous year

From the second year, healthcare utilisation was rapidly reduced and the difference in healthcare utilisation from the second year to fifth year was small. From the second to fifth year, the mean number of days of hospitalisation was $0.3-1.4$ and the mean number of outpatient visit was 1.4-2.5. The number of reconstructive surgery was $0.005-0.012$ per patient and the number of secondary surgeries was $0.015-0.028$ per patient. The mean number of radiotherapy sessions was $0.04-$ 0.08 per patient and the number of chemotherapy sessions was $0.04-0.09$ per patient (Figure 3, 4).

\section{Post-operative healthcare utilisation cost}

Most of the costs were related to inpatient care and inpatient stay was the main cost driver over the 5 year followup. For the five years, cost of inpatient care accounted for $94.7 \%$ of the total cost. The inpatient care cost constituted of hospitalization cost $(84.8 \%)$ and reconstructive surgery $(11.4 \%)$, followed by secondary surgery $(1.5 \%)$, radiotherapy $(0.9 \%)$ and chemotherapy $(0.5 \%)$. Outpatient visits accounted for $94.6 \%$ of outpatient care cost and cost for radiotherapy and chemotherapy accounted for $4.7 \%$ and $0.7 \%$ of outpatient care cost, respectively. The

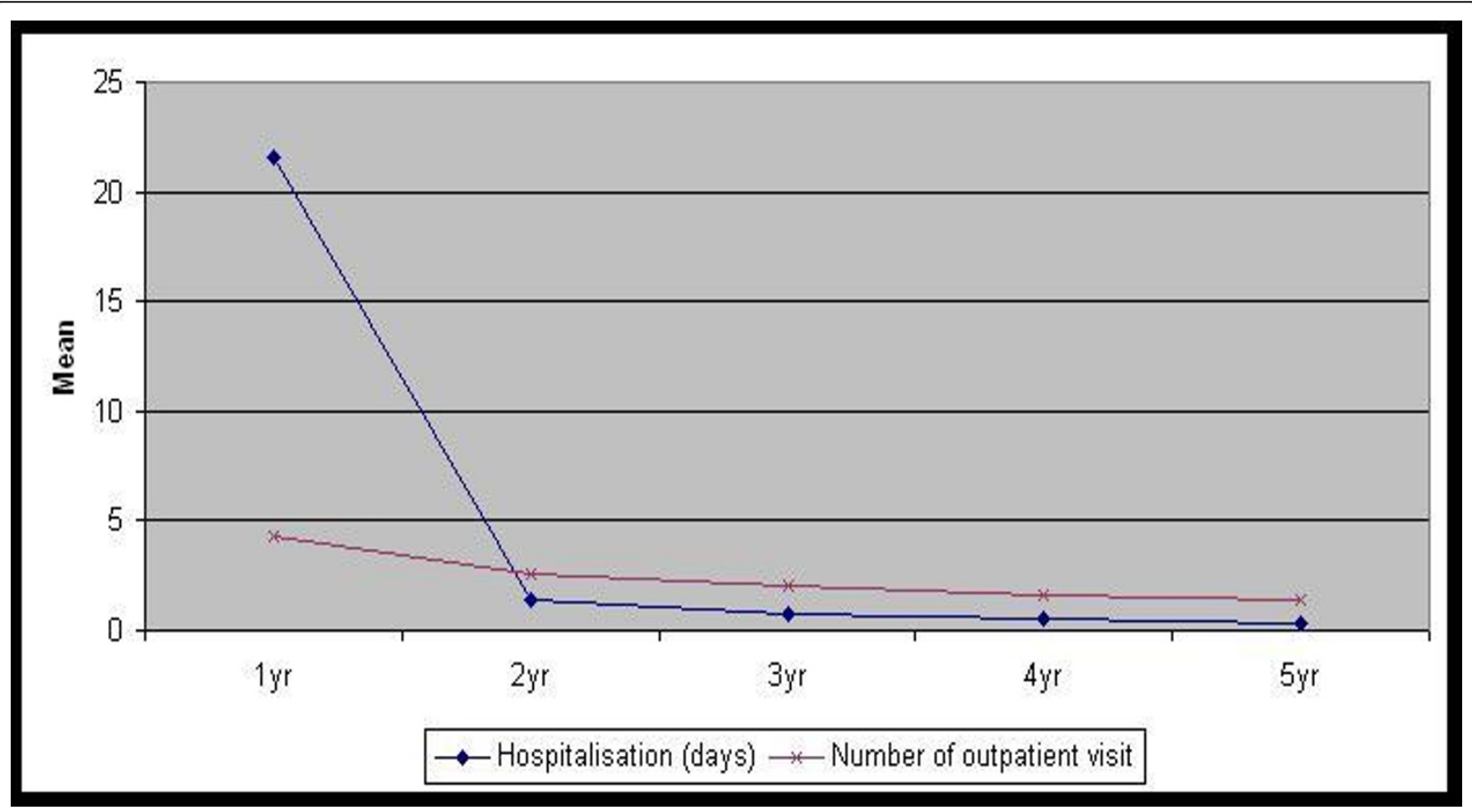

Figure 3 Mean days of hospitalisation and mean number of outpatient visit after surgery over 5 years. Year 1 yr 2 yr 3 yr 4 yr 5 yr. Hospitalisation (days) 21.601 .380 .700 .50 0.30. Number of outpatient visit 4.252 .541 .991 .661 .43$. 


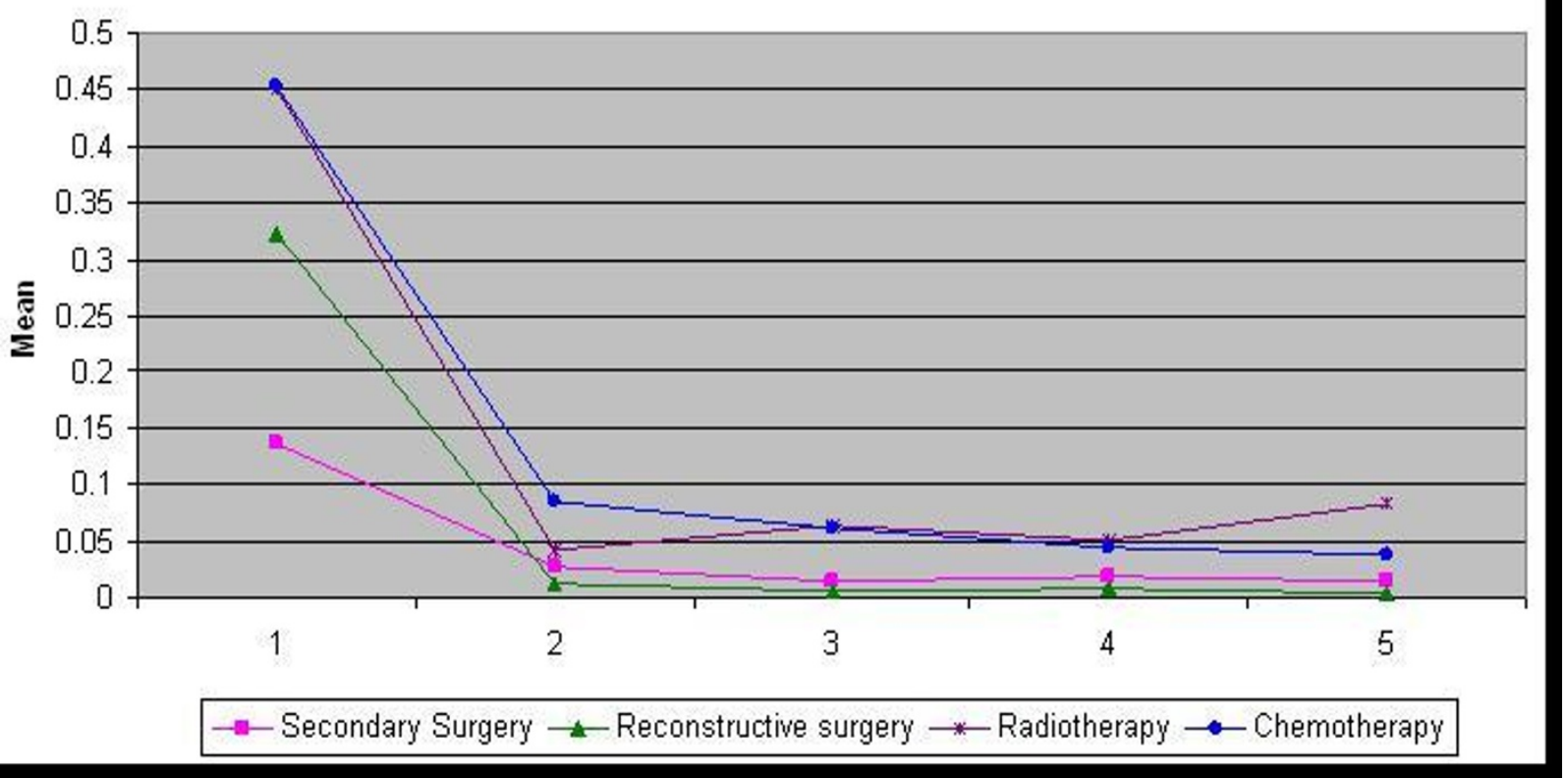

Figure 4 Mean number of healthcare utilisation procedures after surgery over $\mathbf{5}$ years. Year 1 yr 2 yr 3 yr 4 yr 5 yr. Secondary Surgery 0.1370 .0280 .0160 .0200 .015 . Reconstructive surgery 0.3220 .0120 .0070 .0080 .005 . Radiotherapy 0.4510 .0430 .0650 .0520 .084 . Chemotherapy 0.4520 .0850 .0620 .0450 .038 .

mean cost of post-operative healthcare utilisation for the resected patients with SCCHN was $£ 23,212$ over 5 years. The mean cost per year was $£ 19,778$ for the first year, $£ 1,477$ for second year, $£ 847$ for third year, $£ 653$ for fourth year and $£ 455$ for the fifth year (Table 4). The post-operative treatment for larynx cancer was most costly, $£ 28,981$ over 5 years, followed by pharynx cancer $(£ 25,827)$, oral cavity cancer $(£ 25,311)$, tongue cancer $(£ 19,493)$ and lip cancer $(£ 5,790)$ (Table 5). The total cost of the post-operative healthcare utilisation for the cohort of resected SCCHN was estimated to be $£ 255.5$ million over the 5 -year follow-up.

\section{Discussion}

The findings in the analysis were based on a large cohort of patients who were resected for SCCHN between 2003 and 2009. The patient group seemed representative of the resected SCCHN population in the UK. Rogers et al., estimated a 5 year survival rate by the Kaplan-Meier survival analyses among patients who underwent primary surgery for oral cancer during 1992-2002 in the UK [29]. Among the patients during 2000-2 in the study, overall survival rates at 2 year and 5 year were $74 \%$ and $64 \%$, respectively. In the study cohort, overall survival rates at 2 year and 5 year were $74.0 \%$ and $64.9 \%$, respectively, and among the resected oral cancer patients (tongue and oral cavity cancer only), overall survival rates at 2 year and 5 year were $74.2 \%$ and $65.7 \%$, respectively. According to a comparative report of Scottish and
English cohorts, a treatment modality involving surgery for HNC treatment accounted for $51.3 \%$ and $51.6 \%$ in both cohorts [30]. Among the 38,460 patients with SCCHN extracted from HES data, 14,764 patients $(38.4 \%)$ of them were identified to undergo resection. The difference might be caused by miscellaneous surgeries such as biopsy that was not regarded as surgical resection in the sample selection.

In 2001, van Agthoven reported that the average cost per patient was $€ 21,858$ for $\mathrm{HNC}$ and $€ 27,629$ for the recurrent disease for two years in the Netherlands [31]. Based on $36 \%$ of the relapse rate from a prospective cohort study of patients with SCCHN [32], the weighted average cost would be $€ 23,936$ and it could be converted to $£ 23,066$ in 2009 (1 Euro = $0.89 \mathrm{GBP}$ ) [33]. It was comparable to sum of mean cost per first and second year in the results which was $£ 21,255$. Another study reported that the cost of a major head and neck surgical case was $£ 32,000$ in the UK in 2007, including inpatient cost, resection/reconstructive surgery and also nursing cost, intensive therapy unit, rehabilitation and support service cost which were not included in this analysis [34].

One of the methodological difficulties of using the HES data was that the outpatient care records had limited levels of completeness in procedural and diagnostic recording. Healthcare providers in the UK are required to submit their patient's records to NHS on a regular basis. Mandatory fields in the data submission such as patient identification details and specialty of outpatient 
Table 4 Mean cost of post-operative treatment for resected SCCHN patient per year

\begin{tabular}{|c|c|c|c|c|c|c|}
\hline Followed year after resection & $1 \mathrm{yr}$ & $2 \mathrm{yr}$ & $3 \mathrm{yr}$ & $4 \mathrm{yr}$ & $5 \mathrm{yr}$ & Grand tota \\
\hline Number of patients & 11,403 & 9,697 & 8,433 & 7,774 & 7,399 & 44,706 \\
\hline Secondary Surgery & 208 & 45 & 27 & 29 & 19 & 328 \\
\hline Reconstructive surgery & 2,275 & 85 & 49 & 55 & 38 & 2,502 \\
\hline Radiotherapy & 187 & 4 & 6 & 1 & 2 & 201 \\
\hline Chemotherapy & 67 & 17 & 10 & 11 & 8 & 113 \\
\hline \multicolumn{7}{|l|}{ Chemo related condition } \\
\hline Anemia & 33 & 6 & 3 & 2 & 1 & 45 \\
\hline Neutropenia & 36 & 6 & 3 & 2 & 3 & 49 \\
\hline Thrombocytopenia & 37 & 6 & 3 & 2 & 0 & 48 \\
\hline Nausea/Emesis & 14 & 1 & 1 & 1 & 1 & 18 \\
\hline Mucositis & 5 & 0 & 0 & 0 & 1 & 6 \\
\hline \multirow[t]{2}{*}{ Pain } & 19 & 3 & 3 & 0 & 0 & 26 \\
\hline & 144 & 23 & 13 & 7 & 5 & 192 \\
\hline Inpatient stay & 16,448 & 1,050 & 536 & 378 & 230 & 18,642 \\
\hline Inpatient care cost $(£)$ & 19,330 & 1,224 & 641 & 482 & 302 & 21,978 \\
\hline \multicolumn{7}{|l|}{ Outpatient visit } \\
\hline General surgery & 16 & 15 & 16 & 13 & 13 & 73 \\
\hline Oral surgery & 244 & 128 & 94 & 75 & 63 & 603 \\
\hline Restorative dentistry & 24 & 25 & 17 & 16 & 13 & 95 \\
\hline Oral and maxillo facial surgery & 27 & 20 & 16 & 16 & 15 & 94 \\
\hline Plastic surgery & 11 & 6 & 5 & 5 & 4 & 31 \\
\hline Pain management & 0 & 0 & 0 & 0 & 0 & 0 \\
\hline General medicine & 27 & 23 & 23 & 20 & 16 & 109 \\
\hline Palliative medicine & 14 & 12 & 9 & 5 & 8 & 48 \\
\hline Medical oncology & 50 & 20 & 17 & 13 & 10 & 111 \\
\hline \multirow[t]{2}{*}{ Radiology } & 1 & 0 & 0 & 0 & 0 & 2 \\
\hline & 414 & 249 & 198 & 163 & 143 & 1,167 \\
\hline Radiotherapy & 34 & 4 & 7 & 5 & 8 & 57 \\
\hline Chemotherapy & 1 & 0 & 1 & 3 & 3 & 9 \\
\hline Outpatient care cost $(£)$ & 448 & 254 & 206 & 172 & 153 & 1,233 \\
\hline Total cost $(£)$ & 19,778 & 1,477 & 847 & 653 & 455 & 23,212 \\
\hline
\end{tabular}

care typically achieved a high level of completeness but optional fields still needed to be improved [24]. According to the HES outpatient data quality report [35], 97\% of primary diagnosis were recorded as unknown and 93\% of the main procedure/intervention was recorded as "not known" from the outpatient record in 2006-07. Thus, outpatient visit for radiotherapy and chemotherapy might be underestimated where "not known" was recorded for radiotherapy and chemotherapy-related procedures. On the other hand, the mean number of outpatient visit per year seemed to be consistent with other studies. According to a recent study of the trend of follow-up for patients with $\mathrm{HNC}$ in the UK, the number of follow-up appointments for patients were reported to once every 3-6 months in the third year and once every 6-12 months in the fourth and fifth year [36] and the findings were similar with the frequency of the outpatient visit identified in the sample population.

\section{Conclusion}

This retrospective data analysis was performed and based on a large number of empirical patient records from in- and outpatient care, and the study population seemed to be representative for resected SCCHN patients in the UK. Almost 38\% of SCCHN patients underwent surgical resection and the resected patients had a high mortality rate. The patients with SCCHN needed considerable healthcare resources after surgical resection, associated with substantial costs. Over the 5year follow-up period, $85 \%$ of costs occurred in the first year following the first surgical resection. Since outpatient-based radiotherapy and chemotherapy utilisation seemed to be underestimated, the outpatient cost of post-operative healthcare utilisation was likely to be even higher. Nevertheless, the average total cost of postoperative healthcare utilisation appeared to be comparable to previous studies. 
Table 5 Mean cost of post-operative treatment for resected SCCHN patient by cancer site

\begin{tabular}{|c|c|c|c|c|c|c|}
\hline Followed year after resection & Lip & Tongue & Oral cavity & Pharynx & Larynx & SCCHN \\
\hline Number of patients & 1,250 & 2,167 & 2,372 & 2,304 & 3,310 & 11,403 \\
\hline Secondary Surgery & 176 & 328 & 318 & 185 & 489 & 328 \\
\hline Reconstructive surgery & 2,368 & 2,152 & 5,411 & 2,283 & 843 & 2,502 \\
\hline Radiotherapy & 38 & 203 & 183 & 325 & 189 & 201 \\
\hline Chemotherapy & 13 & 110 & 82 & 217 & 92 & 113 \\
\hline \multicolumn{7}{|l|}{ Chemo related condition } \\
\hline Anemia & 4 & 45 & 53 & 71 & 37 & 45 \\
\hline Neutropenia & 6 & 78 & 32 & 101 & 23 & 49 \\
\hline Thrombocytopenia & 5 & 56 & 48 & 82 & 37 & 48 \\
\hline Nausea/Emesis & 3 & 16 & 15 & 43 & 10 & 18 \\
\hline Mucositis & 3 & 6 & 14 & 9 & 1 & 6 \\
\hline \multirow[t]{2}{*}{ Pain } & 2 & 29 & 26 & 28 & 32 & 26 \\
\hline & 23 & 230 & 188 & 333 & 139 & 192 \\
\hline Inpatient stay & 2,180 & 14,888 & 16,961 & 21,424 & 26,691 & 18,642 \\
\hline Inpatient care cost $(£)$ & 4,798 & 17,910 & 23,143 & 24,766 & 28,443 & 21,978 \\
\hline \multicolumn{7}{|l|}{ Outpatient visit } \\
\hline General surgery & 87 & 66 & 78 & 61 & 77 & 73 \\
\hline Oral surgery & 508 & 959 & 1,337 & 337 & 55 & 603 \\
\hline Restorative dentistry & 38 & 88 & 206 & 116 & 29 & 95 \\
\hline Oral and maxillo facial surgery & 68 & 167 & 200 & 52 & 9 & 94 \\
\hline Plastic surgery & 124 & 22 & 21 & 22 & 14 & 31 \\
\hline Pain management & 0 & 0 & 0 & 0 & 0 & 0 \\
\hline General medicine & 107 & 98 & 101 & 99 & 130 & 109 \\
\hline Palliative medicine & 9 & 43 & 39 & 91 & 45 & 48 \\
\hline Medical oncology & 38 & 90 & 94 & 164 & 129 & 111 \\
\hline \multirow[t]{2}{*}{ Radiology } & 1 & 2 & 2 & 3 & 1 & 2 \\
\hline & 980 & 1,535 & 2,078 & 943 & 490 & 1,167 \\
\hline Radiotherapy & 11 & 46 & 80 & 107 & 34 & 57 \\
\hline Chemotherapy & 1 & 2 & 9 & 11 & 14 & 9 \\
\hline Outpatient care cost $(£)$ & 992 & 1,583 & 2,168 & 1,061 & 538 & 1,233 \\
\hline Total cost $(£)$ & 5,790 & 19,493 & 25,311 & 25,827 & 28,981 & 23,212 \\
\hline
\end{tabular}

These findings might provide a useful source for clinicians and decision makers in understanding the economic burden of managing SCCHN in the UK and also suggests a need for new therapies that could improve outcomes and reduce the disease burden.

\section{Additional material}

Additional file 1: Unit costs for procedures from inpatient and outpatient care. The unit costs for the post-operative healthcare cost were based on "the national schedule of reference costs 2008-09 for NHS Trusts" and "Unit costs of health \& social care 2009 " published by PSSRU.

\section{List of abbreviations}

HNC: Head and Neck Cancer; HES: Hospital Episode Statistic; KMSA: the Kaplan-Meier Sample-Average; NHS: National Health Service; ONS: the Office for National Statistics; PSSRU: the Personal Social Services Research Unit; QoL: Quality of Life; SCCHN: Squamous Cell Carcinoma of the Head and Neck.

\section{Acknowledgements}

Nicolas Despiégel (Optumlnsight, Uxbridge in UK) retrieved the patient records extracted from HES and he implemented the primary statistic analysis.

\section{Author details}

${ }^{1}$ Optumlnsight, Stockholm, Sweden. ${ }^{2}$ GlaxoSmithKline, Collegeville, PA, USA.

${ }_{3}^{3}$ i Innovus (currently OptumInsight), Stockholm, Sweden.

\section{Authors' contributions}

KK has made contributions to the study design, analysis and interpretation of data and drafting and revising the manuscript. MMA has been in involved in conception and design of the study. DH participated in drafting and revising the manuscript. FK has contributed to conception and design of the study. All authors have read and approved the final manuscript.

\section{Competing interests}

This analysis was financially supported by GlaxoSmithKline. Mayur Amonkar is an employee of GlaxoSmithKline.

Received: 10 October 2011 Accepted: 28 October 2011 Published: 28 October 2011 
References

1. Ferlay J: GLOBOCAN 2002. Cancer Incidence, Mortality and Prevalence Worldwide. IARC CancerBase 2004, 5(version 2.0).

2. Cancer Research UK: CancerStats. 2009

3. Conway DI, Stockton DL, Warnakulasuriya KA, Ogden G, Macpherson LM: Incidence of oral and oropharyngeal cancer in United Kingdom (19901999) - recent trends and regional variation. Oral Oncol 2006 42(6):586-92

4. Brewster DH, Bhatti LA, Inglis JHC, Nairn ER, Doherty VR: Recent trends in incidence of nonmelanoma skin cancers in the East of Scotland, 19922003. British Journal of Dermatology 2007, 156(6):1295-300.

5. Doobaree IU, Landis SH, Linklater KM, El-Hariry I, Moller H, Tyczynski J: Head and neck cancer in South East England between 1995-1999 and 20002004: An estimation of incidence and distribution by site, stage and histological type. Oral Oncol 2009, 45(9):809-14.

6. Hassan MA, Lund VJ, Howard DJ, Sacker AA: Are the demographics for squamous cell cancer in the head and neck changing in the United Kingdom? Journal of Laryngology and Otology 2007, 121(2):154-7.

7. Coupland VH, Chapman P, Linklater KM, Sehgal A, Moller H, Davies EA: Trends in the epidemiology of larynx and lung cancer in south-east England, 1985-2004. Br J Cancer 2009, 100(1):167-9.

8. La VC, Lucchini F, Negri E, Levi F: Trends in oral cancermortality in Europe. Oral Oncology 2004, 40(4):433-9.

9. Olsen AH, Parkin DM, Sasieni P: Cancer mortality in the United Kingdom projections to the year 2025. Br J Cancer 2008, 99(9):1549-54.

10. Andersen $\mathrm{ZJ}$, Lassen CF, Clemmensen $\mathrm{IH}$ : Social inequality and incidence of and survival from cancers of the mouth, pharynx and larynx in a population-based study in Denmark, 1994-2003. Eur J Cancer 2008, 44(14):1950-61.

11. Biazevic MGH, Antunes JLF, Togni J, de Andrade FP, de Carvalho MB, Wunsch-Filho V: Immediate Impact of Primary Surgery on Health-Related Quality of Life of Hospitalized Patients With Oral and Oropharyngeal Cancer. Journal of Oral and Maxillofacial Surgery 2008, 66(7):1343-50.

12. Lloyd S, Devesa-Martinez P, Howard DJ, Lund VJ: Quality of life of patients undergoing surgical treatment of head and neck malignancy. Clinical Otolaryngology and Allied Sciences 2003, 28(6):524-32

13. Starska K, Ciechomska EA, Lukomski M: Quality of life in patients with laryngeal carcinoma after radical neck dissection. Otolaryngologia polska The Polish otolaryngology 2003, 57(5):667-73.

14. Rogers SN, Gwanne S, Lowe D, Humphris G, Yueh B, Weymuller J: The addition of mood and anxiety domains to the University of Washington quality of life scale. Head and Neck 2002, 24(6):521-9.

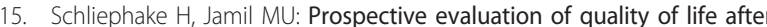
oncologic surgery for oral cancer. International Journal of Oral and Maxillofacial Surgery 2002, 31(4):427-33.

16. Kessler PA, Bloch-Birkholz A, Leher A, Neukam FW, Wiltfang J: Evaluation of quality of life of patients with oral squamous cell carcinoma. Comparison of two treatment protocols in a prospective study Radiotherapy and Oncology 2004, 70(3):275-82

17. Markkanen-Leppanen M, Makitie AA, Haapanen M-L, Suominen E, AskoSeljavaara S: Quality of life after free-flap reconstruction in patients with oral and pharyngeal cancer. Head and Neck 2006, 28(3):210-6.

18. Bian X, Xu ZG, Lu CM, Tang PZ, Luo J: [Cancer and surgical treatment impact the quality of life in patients with head and neck cancer]. Zhonghua Er Bi Yan Hou Tou Jing Wai Ke Za Zhi 2005, 40(8):606-10.

19. Liu L-T, Li L, Qiu Y-Z: Evaluation on the quality of life of the patients with laryngeal neoplasms of partial laryngectomy and its influencing factors. Chinese Journal of Clinical Rehabilitation 2004, 8(29):6314-5.

20. Tas A, Yagiz R, Karasalihoglu AR, Koten M, Adali MK, Uzun C: Assessment of quality of life in patients with laryngeal cancer after surgical treatment. Kulak burun bogaz ihtisas dergisi 2004, 12(3-4):84-90.

21. Zhang L, Luan X, Pan X, Xie G, Xu F, Liu D, et al: Quality of life following laryngectomy. Zhonghua er bi yan hou ke za zhi 2002, 37(1):11-4

22. Sewnaik $A$, van den Brink $J$, Wieringa MH, Meeuwis CA, Kerrebijn JDF: Surgery for recurrent laryngeal carcinoma after radiotherapy: Partial laryngectomy or total laryngectomy for a better quality of life? Otolaryngology - Head and Neck Surgery 2005, 132(1):95-8.

23. Murphy BA, Chen A, Curran WJ Jr, Garden AS, Harari PM, Wong SJ, et al: Longitudinal oncology registry of head and neck carcinoma (LORHAN): initial supportive care findings. Support Care Cancer 2009, 17(11):1393-401.
24. NHS. Reporting patient journeys: Hospital outpatient activity in 2003-04 and 2005-05; First report and quality assessment of experimental data from patient level record system. The Information Centre 2006.

25. Hospital Episode Statistic (HES) in the UK: HES Accident and Emergency Data Quality Note 2008-09. 2010.

26. Blackhouse $G$, Briggs $A H$, O'Brien $B J$ : A note on the estimation of confidence intervals for cost-effectiveness when costs and effects are censored. Med Decis Making 2002, 22(2):173-7

27. Cancer Research UK: Laryngeal (larynx) cancer - UK incidence statistics in 2007. 2011 [http://www.cancerresearchuk.org/]

28. Cancer Research UK: Oral cancer - UK incidence statistics in 2007. 2011 [http://www.cancerresearchuk.org/].

29. Rogers SN, Brown JS, Woolgar JA, Lowe D, Magennis P, Shaw RJ, et al: Survival following primary surgery for oral cancer. Oral Oncology 2009 45(3):201-11.

30. MacKenzie K, Savage SA, Birchall MA: Processes and outcomes of head and neck cancer patients from geographically disparate regions of the UK. A comparison of Scottish and English cohorts. Eur J Surg Oncol 2009, 35(10):1113-8

31. Van AM, van Ineveld BM, De Boer MF, Leemans CR, Knegt PP, Snow GB, et al: The costs of head and neck oncology: primary tumours, recurrent tumours and long-term follow-up. Eur J Cancer 2001, 37(17):2204-11.

32. Hall SF, Groome PA, Rothwell D: Time to first relapse as an outcome and a predictor of survival in patients with squamous cell carcinoma of the head and neck. Laryngoscope 2000, 110(12):2041-6.

33. CBS: Central Bureau of Statistics: Cusumer Price Index (CPI) with health care in the Netherlands. 2011 [http://statline.cbs.nl/statweb/].

34. Jeannon JP, Abbs I, Calman F, Gleeson M, Lyons A, Hussain K, et al: Implementing the National Institute of Clinical Excellence improving outcome guidelines for head and neck cancer: developing a business plan with reorganisation of head and neck cancer services. Clin Otolaryngol 2008, 33(2):149-51.

35. Hospital Episode Statistics (HES) in the UK: HES outpatient data quality report. 2010.

36. Joshi A, Calman F, O'Connell M, Jeannon JP, Pracy P, Simo R: Current Trends in the Follow-up of Head and Neck Cancer Patients in the UK. Clin Oncol (R Coll Radiol) 2010, 22(2):114-8.

doi:10.1186/1758-3284-3-47

Cite this article as: Kim et al:: Economic burden of resected squamous cell carcinoma of the head and neck in an incident cohort of patients in the UK. Head \& Neck Oncology 2011 3:47.

\section{Submit your next manuscript to BioMed Central and take full advantage of:}

- Convenient online submission

- Thorough peer review

- No space constraints or color figure charges

- Immediate publication on acceptance

- Inclusion in PubMed, CAS, Scopus and Google Scholar

- Research which is freely available for redistribution

Submit your manuscript at www.biomedcentral.com/submit
C Biomed Central 